\title{
Microstructure and Mechanical Properties of RAFM-316L Dissimilar Joints by Friction Stir Welding with Different Butt Joining Modes
}

\author{
Bin $\mathrm{He}^{1} \cdot$ Lei Cui $^{1} \cdot$ Dong-Po Wang ${ }^{1} \cdot$ Hui-Jun $\mathrm{Li}^{1} \cdot$ Chen-Xi Liu $^{1}$
}

Received: 31 March 2019 / Revised: 1 July 2019 / Published online: 10 October 2019

(C) The Chinese Society for Metals (CSM) and Springer-Verlag GmbH Germany, part of Springer Nature 2019

\begin{abstract}
Dissimilar welded joints of reduced activation ferritic/martensitic (RAFM) steel and 316L austenitic stainless steel were prepared by friction stir welding with different butt joining modes and welding parameters. The weld quality of the joint was improved by placing the $316 \mathrm{~L}$ steel on the advancing side and the RAFM steel on the retreating side, and using a relatively high rotational speed of $400 \mathrm{rpm}$. The microstructure of the stir zone on the $316 \mathrm{~L}$ steel side consisted of single-phase austenite, and the microstructure of the stir zone on the RAFM steel side mainly consisted of lath martensite and equiaxed ferrite. A mechanical mixture of the two steels and diffusion of $\mathrm{Cr}$ and $\mathrm{Ni}$ could be detected near the bonding interface. Diffusion of $\mathrm{Ni}$ from the 316 steel to the RAFM steel resulted in the formation of a dual-phase structure consisting of austenite and ferrite. The as-welded joints showed good strength and ductility at room temperature and $550{ }^{\circ} \mathrm{C}$, which were nearly equal to those of the $316 \mathrm{~L}$ base material. The heat-affected zone on the RAFM side had the lowest impact toughness throughout the weld with a value of $13.2 \mathrm{~J}$ at $-40{ }^{\circ} \mathrm{C}, \sim 52 \%$ that of the RAFM base material.
\end{abstract}

Keywords Friction stir welding $\cdot$ Dissimilar joint $\cdot$ RAFM steel $\cdot$ 316L steel $\cdot$ Microstructures $\cdot$ Mechanical properties

\section{Introduction}

Reduced activation ferritic/martensitic (RAFM) steel and austenitic stainless steel are believed to be two structural materials that can be used for the back wall in test blanket modules (TBMs) because of their good high-temperature properties [1]. RAFM steel evolved from conventional 9\% $\mathrm{Cr}$ heat-resistant steels by replacing Mo and $\mathrm{Nb}$ with lowactivity elements of Ta and $\mathrm{W}$ that play an important role in solid solution strengthening and precipitation strengthening of the steel at high temperatures $[2,3]$. Welding the above two materials is necessary when building a nuclear reactor, such as for the connection of vacuum vessels and cooling pipes [4]. Therefore, there is substantial interest in welding them together.

Available online at http://link.springer.com/journal/40195

Lei Cui

leicui@tju.edu.cn

1 Tianjin Key Laboratory of Advanced Joining Technology, School of Materials Science and Engineering, Tianjin University, Tianjin 300354, China
Various fusion welding technologies for producing $316 \mathrm{~L}$ steel and RAFM steel dissimilar joints have been proposed in the previous studies, including electron beam welding, tungsten inert welding, and laser welding [5, 6]. However, during fusion welding process of such two materials, the dilution of the chemical composition of the weld seam, hot cracking and hydrogen-induced cracking, grain coarsening and precipitation of the Cr-rich phase in the heat-affected zone (HAZ) are very difficult to avoid because of the melting and solidification process $[7,8]$.

Friction stir welding (FSW), a solid-state welding process, has been proven to be a viable approach for welding the two steels and exhibited the potential to resolve the problems that occur in the fusion welding process $[9,10]$. When welding dissimilar joints of ST37 steel and 304 steel by FSW, it was found that the stir zone (SZ) of the 304 steel exhibited good strength and ductility because of the grain refinement that occurred as the result of the dynamic recrystallization and rapid cooling during FSW [11]. In the 430-ODS dissimilar FSW joint, the grain growth in the HAZ was very limited. Moreover, in the thermomechanically affected zone (TMAZ), the initial elongated grains of the as-rolled BM transformed to fine-equiaxed grains [3]. Tang et al. [12] obtained defect-free China low activation 
martensitic (CLAM) steel and 316L dissimilar joints by FSW, with the peak temperature and cooling rate in the SZ being controlled to be approximately $1130{ }^{\circ} \mathrm{C}$ and $34{ }^{\circ} \mathrm{C} / \mathrm{s}$, respectively. They also found that the tensile strength of the as-welded joint was equal to that of $316 \mathrm{~L}$ base metal (BM) at room temperature [12].

The present study aims to investigate some other important aspects of FSW for RAFM-316L dissimilar joints, including the butt joining mode of the two materials and the variation of the welding parameters. Moreover, the characteristics of microstructural evolution and the mechanical properties of the FSW joints were examined and evaluated.

\section{Experimental}

RAFM steel plates and 316L stainless steel plates with a thickness of $3.5 \mathrm{~mm}$ were used as the BMs. The chemical compositions of the two BMs are shown in Table 1. Figure 1 shows the initial microstructures of the two BMs before welding. The microstructure of RAFM steel mainly consisted of ferrite and martensite (Fig. 1a), and $M_{23} \mathrm{C}_{6}$ particles precipitated along the grain boundaries of the prior austenite (Fig. 1c). The microstructure of the 316L stainless steel was mainly composed of austenite and contained deformation bands parallel to the rolling direction and some twin crystal structures (Fig. 1b, d).

Four butt joining modes of 316L stainless steel plate and RAFM steel plate were used to examine the influence of their relative positions on the welding qualities. As illustrated in Fig. 2, the first strategy involved placing the RAFM steel on the advancing side (AS) and placing the $316 \mathrm{~L}$ stainless steel on the retreating side (RS), to produce the so-called $R A F M(A S)-316 L(R S)$ weld in this study. The second strategy involved placing the $316 \mathrm{~L}$ stainless steel and the RAFM steel on the AS and RS, respectively, to produce the 316L(AS)$R A F M(R S)$ weld. The third strategy involved offsetting the welding tool by $1 \mathrm{~mm}$ from the joining interface to the

Table 1 Chemical composition of BM-RAFM and BM-316L steel (wt $\%)$

\begin{tabular}{lllllllllll}
\hline & $\mathrm{C}$ & $\mathrm{Cr}$ & $\mathrm{Ni}$ & $\mathrm{Mo}$ & $\mathrm{Mn}$ & $\mathrm{V}$ & $\mathrm{W}$ & $\mathrm{Ta}$ & $\mathrm{Si}$ & $\mathrm{N}$ \\
\hline BM-RAFM & 0.10 & 9.2 & - & - & 0.47 & 0.21 & 1.0 & 0.087 & 0.12 & 0.0083 \\
BM-316L & 0.02 & 16.58 & 12.07 & 2.02 & 0.8 & - & - & - & 0.28 & 0.035 \\
\hline
\end{tabular}
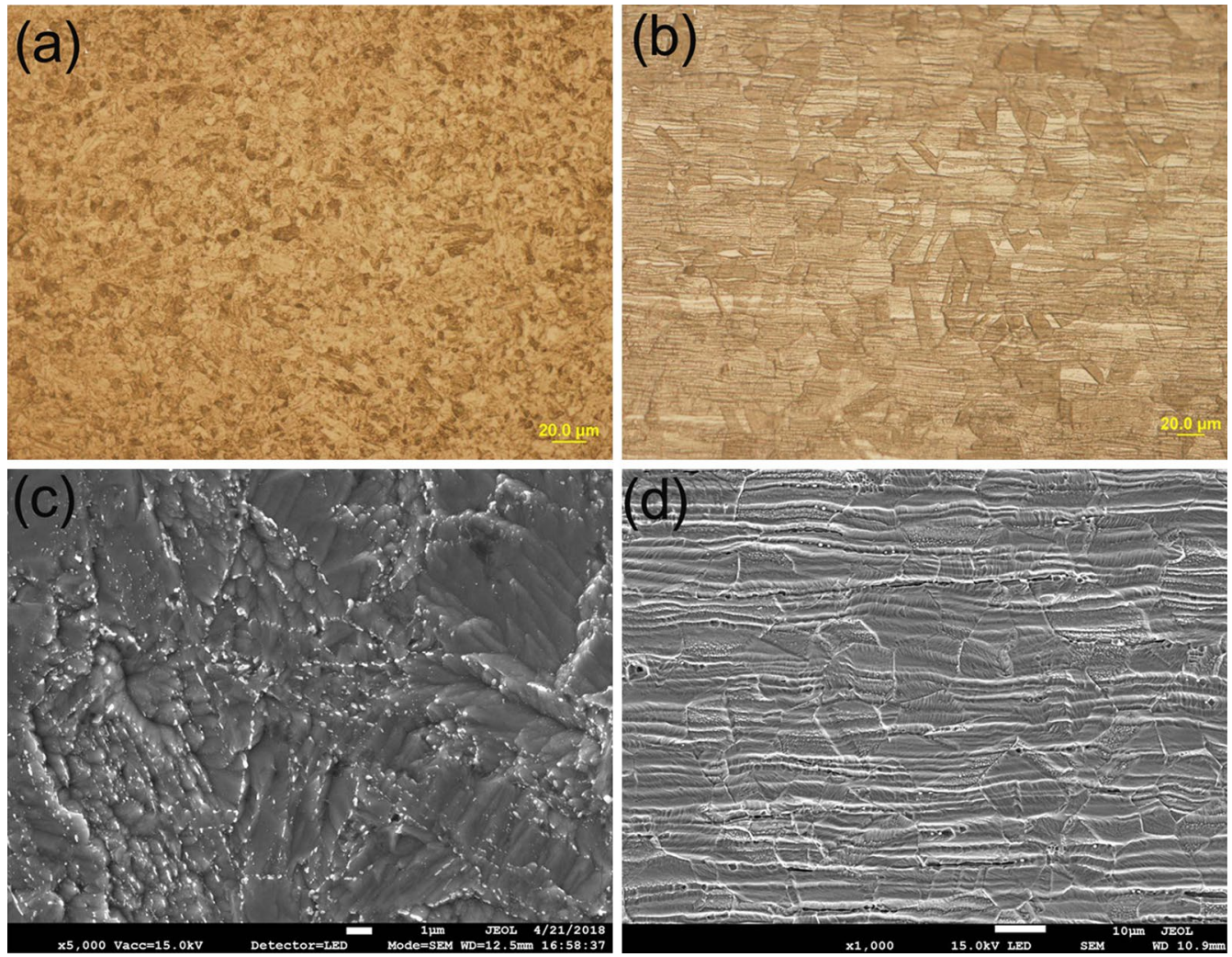

Fig. 1 Microstructures of the base metals: a, c OM and SEM images of RAFM; b, d OM and SEM images of 316L stainless steel 

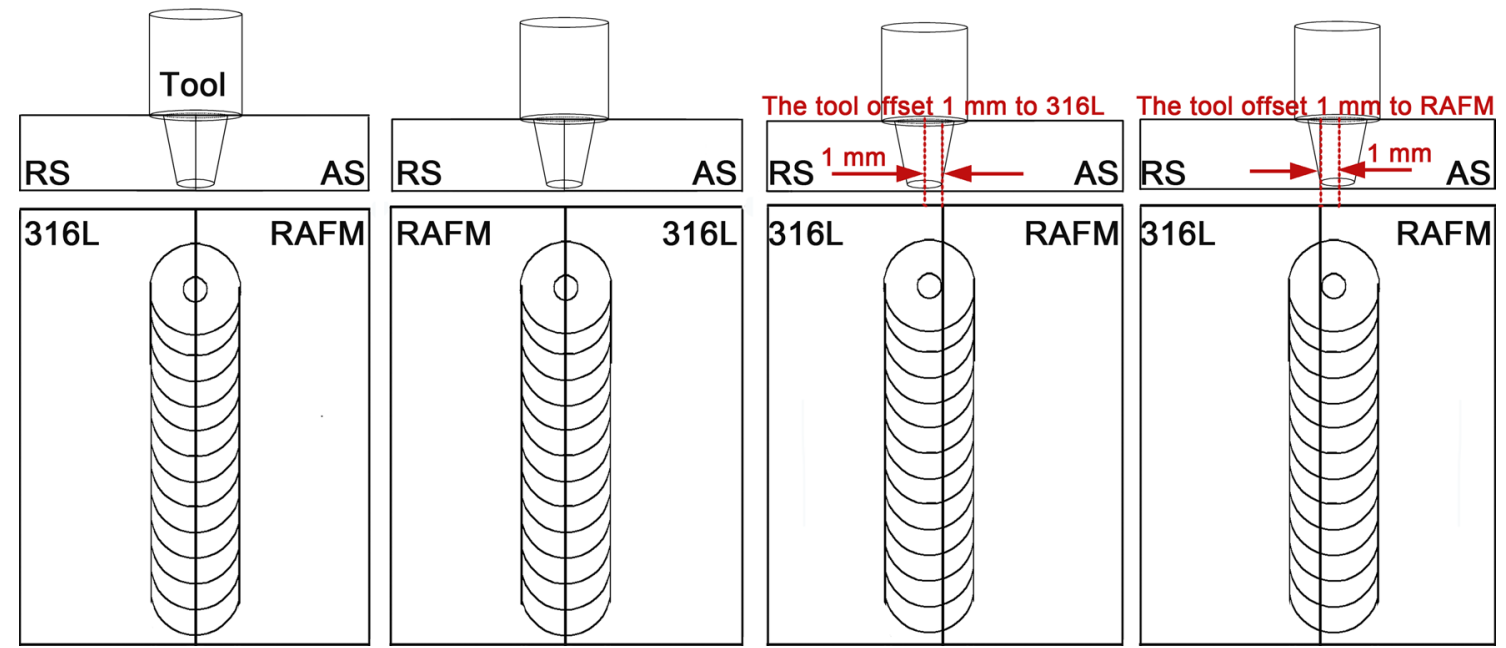

Fig. 2 Relative position of the FSW tool to the weld

Table 2 Butt joining types and the related welding parameters

\begin{tabular}{|c|c|c|c|c|}
\hline $\begin{array}{l}\text { Butt joining types in } \\
\text { FSW }\end{array}$ & $\begin{array}{l}\text { Rotational } \\
\text { speed (rpm) }\end{array}$ & $\begin{array}{l}\text { Travel } \\
\text { speed }(\mathrm{mm} / \\
\text { min) }\end{array}$ & $\begin{array}{l}\text { Tool tilt } \\
\text { angle }\left({ }^{\circ}\right)\end{array}$ & $\begin{array}{l}\text { Axial } \\
\text { load } \\
(\mathrm{kN})\end{array}$ \\
\hline$R A F M(A S)-316 L(R S)$ & 300 & 75 & 2.5 & 10 \\
\hline $316 L(A S)-R A F M(R S)$ & 300 & 75 & 2.5 & 10 \\
\hline $\begin{array}{l}R A F M(A S+1)- \\
316 L(R S)\end{array}$ & 300 & 75 & 2.5 & 10 \\
\hline $\begin{array}{l}R A F M(A S)- \\
316 L(R S+1)\end{array}$ & 300 & 75 & 2.5 & 10 \\
\hline$R A F M(A S)-316 L(R S)$ & 400 & 100 & 2.5 & 10 \\
\hline $316 L(A S)-R A F M(R S)$ & 400 & 100 & 2.5 & 10 \\
\hline
\end{tabular}

RAFM on the AS to produce the RAFM(AS+1)-316L(RS) weld. The last strategy involved offsetting the welding tool by $1 \mathrm{~mm}$ offset from the joining interface to the 316L stainless steel on the RS to produce the RAFM(AS)-316L(RS+1) weld. The corresponding FSW parameters for each of the conditions are shown in Table 2.

The welding experiments were carried out on an FSW3LM-020 machine. The FSW tool was made of W-25\% Re alloy and consisted of a 15-mm-diameter concave shoulder and a 3-mm-long tapered and screwed probe. The welding parameters were $300-400 \mathrm{rpm}$ rotational speeds, $75-100 \mathrm{~mm} / \mathrm{min}$ travel speeds, $2.5^{\circ}$ tool tilt angle, and 10 $\mathrm{kN}$ axial force, as shown in Table 2.

The as-welded workpieces were cross-sectioned to examine the weld formation and microstructures of the joints. The cross-sectioned samples were then mechanically ground, polished and etched with a solution of $5 \mathrm{~g} \mathrm{FeCl}_{3}, 20 \mathrm{~mL}$ $\mathrm{HCl}$, and $100 \mathrm{~mL}$ water for $90 \mathrm{~s}$. Microstructural observations were conducted on an OLYMPUS GX51 optical microscopy $(\mathrm{OM})$ and a Hitachi-S4800 scanning electron microscopy (FE-SEM). Energy-dispersive spectroscopy (EDS) was used to analyze the element distribution near the bonding interface. To examine the microstructures of the $\mathrm{SZ}$ at a higher magnification, a Tecnai G2F30 transmission electron microscopy (TEM) was used.

The hardness distribution of the weld, from the AS to the RS with an interval of $0.5 \mathrm{~mm}$, was obtained by HV10 hardness testing with a HV-1000A microhardness tester. The tensile specimens were cut from the friction stir welded joints, as shown in Fig. 3a, c. The tensile properties of the weld were tested on a CSS-44100 universal tensile testing machine at room temperature and $550{ }^{\circ} \mathrm{C}$. The impact toughness of the joint was evaluated with $\mathrm{V}$-notched impact testing at a temperature of $-40{ }^{\circ} \mathrm{C}$, as shown in Fig. 3b, c.

\section{Results and Discussion}

\subsection{Weld Formation}

Figure $4 \mathrm{a}, \mathrm{b}$ shows the $\mathrm{OM}$ images of the cross sections for $R A F M(A S)-316 L(R S)$ and 316L(AS)-RAFM(RS) joints, which were welded with a rotational speed of $300 \mathrm{rpm}$ and a travel speed of $75 \mathrm{~mm} / \mathrm{min}$. The relative position of the two BMs had a significant effect on the weld formation. In the $R A F M(A S)-316 L(R S)$ joint, as shown in Fig. 4a, the extent of material flow in the upper part of the SZ was relatively broad. However, it seemed insufficient in the lower part of the SZ when using a tool with a tapered probe. The above characteristics agreed well to the results obtained by Gao et al. [13] and Cho et al. [14] that the velocity of material flow in the SZ around the tool probe at the upper part was higher than that at the lower part during FSW because a tapered tool probe was used. If the material flow in the SZ 

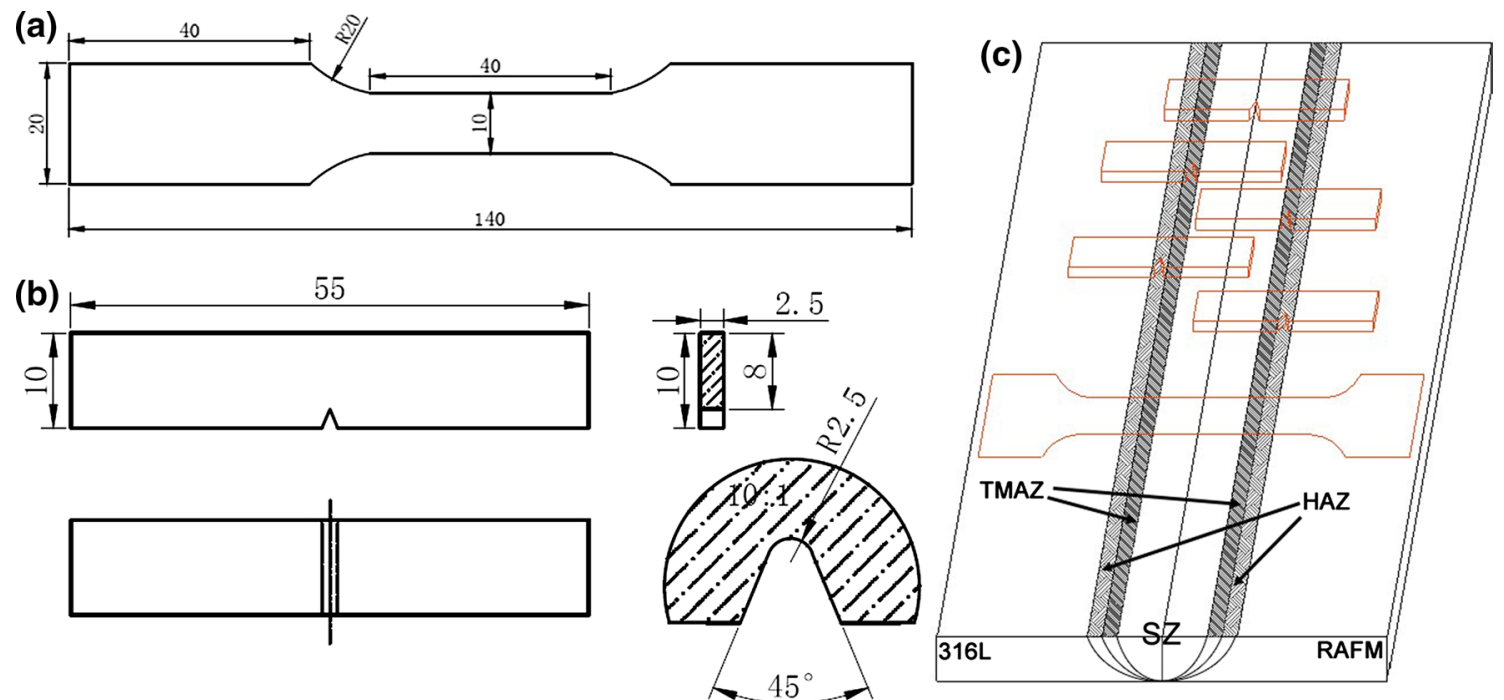

Fig. 3 Dimensions of specimens for a tension, b V-notch Charpy impact, $\mathbf{c}$ schematic of sampling locations
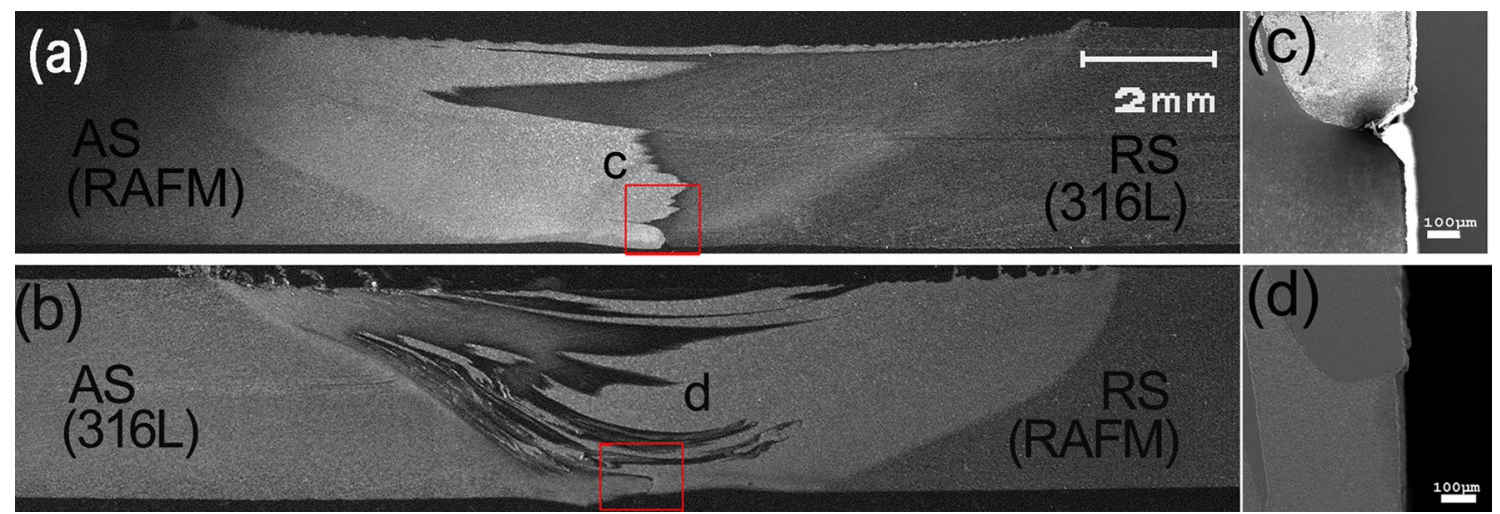

Fig. 4 Cross sections of RAFM-316L dissimilar FSW joint at $300 \mathrm{rpm}$ rotational speed and $75 \mathrm{~mm} / \mathrm{min}$ travel speed: a $R A F M(A S)-316 L(R S)$, b $316 L(A S)-R A F M(R S), \mathbf{c}, \mathbf{d}$ SEM images of rectangular regions $\mathbf{c}$ and $\mathbf{d}$ in $\mathbf{a}$ and $\mathbf{b}$, respectively

was insufficient, a lack of bonding defect might form at the root of the as-welded joint (Fig. 4c).

As can be seen in the $316 L(A S)-R A F M(R S)$ joint (Fig. 4b), when the 316L stainless steel was placed on the AS, lack of bonding defects could no longer be observed at the weld root (Fig. 4d). The cross-sectioning observations also indicated that using the $316 L(A S)$ - RAFM(RS) mode could improve the material flow in the SZ and was helpful to eliminate lack of bonding defects in the joints. It was also found that the width of the HAZ on the RAFM steel side was wider than that on the $316 \mathrm{~L}$ stainless steel side, regardless of which butt joining mode was used. This was because the thermal stability of the 316L stainless steel with the single-phase austenite structure was greater than that of the RAFM steel.

As proposed in the previous studies, during the FSW of steels, the heat generation and welding peak temperature on the AS were generally greater those on the RS $[15,16]$. When welding the dissimilar joint by placing the harder material on the AS, the flow stress of materials in the SZ could be reduced owing to that the temperature on the AS was higher than that on the RS [9, 10]. Huang et al. [17] proposed that the plasticized materials flowed from the AS to the RS on the leading side of the tool probe, while the materials flowed from the RS to the AS behind the tool probe to fill the hole during the FSW process. When placing the $316 \mathrm{~L}$ stainless steel on the AS, the material flow ahead the tool probe and backfilling of materials behind the tool probe became easier during the FSW process. Therefore, when welding 316L-RAFM dissimilar joints, to enhance the material flow in the SZ and remove the weld root defects, the butt joining mode of $316 L(A S)-R A F M(R S)$ is recommended.

Figure $5 \mathrm{a}, \mathrm{b}$ shows the cross-sectional microstructures of the RAFM(AS)-316L(RS) joint and 316L(AS)-RAFM(RS) 


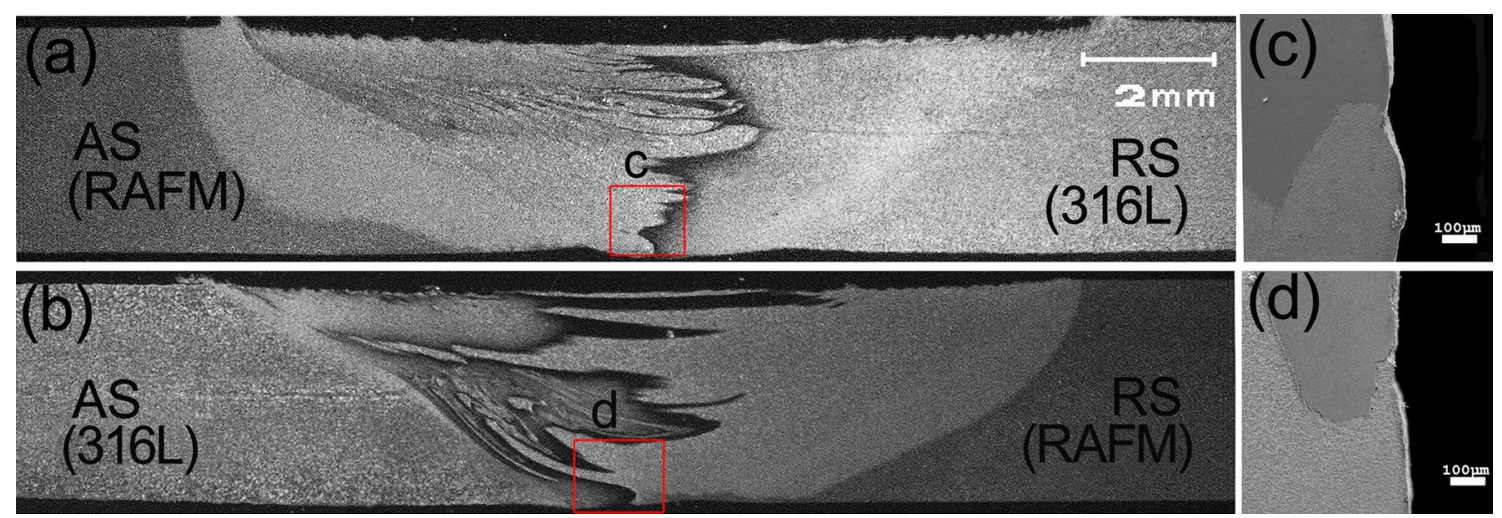

Fig. 5 Cross sections of RAFM-316L dissimilar FSW joint at a rotational speed of $400 \mathrm{rpm}$ and travel speed of $100 \mathrm{~mm} / \mathrm{min}$ : a $R A F M(A S)$ $316 L(R S), \mathbf{b} 316 L(A S)-R A F M(R S), \mathbf{c}, \mathbf{d}$ SEM images of rectangular regions $\mathbf{c}$ and $\mathbf{d}$ in $\mathbf{a}$ and $\mathbf{b}$, respectively

joint, welded with $400 \mathrm{rpm}$ rotational speed and $100 \mathrm{~mm} /$ min travel speed. It can be seen that, since the rotational speed increased from $300 \mathrm{rpm}$ to $400 \mathrm{rpm}$, the mixing of the two materials in the SZ and the weld root formation was improved simultaneously (Fig. 5c, d). It is because the heat generation and material flow in the SZ during FSW were enhanced when a higher rotational speed was used. Compared with the results shown in Fig. 4, it can be found that the increase in the rotational speed showed more significant influence on improving the weld formation, although the heat inputs which could be estimated by the ratio of rotational speed to travel speed are nearly equal. Therefore, increasing the rotational speed appropriately is recommended when welding 316L-RAFM dissimilar joints by FSW.

Figure $6 \mathrm{a}, \mathrm{b}$ shows the cross-sectional microstructures of the $R A F M(A S+1)-316 L(R S)$ and $R A F M(A S)-316 L(R S+1)$ joints when the tool probe was offset $1 \mathrm{~mm}$ from the joining interface to the RAFM steel side and $1 \mathrm{~mm}$ from the joining interface to the 316L stainless steel side, respectively. It can be seen that offsetting the tool probe had a very limited influence on the extent of material flow in the SZ (Figs. 4 and 6). However, because the stirring action of the tool probe was insufficient, effective bonding of the two materials at the bottom of the weld interface was not achieved and may have led to poor bonding quality at the weld root (Fig. 6c, d).

Based on the above results, it is believed that placing 316L stainless steel on the AS and using a relatively high tool rotational speed can improve the material flow in the SZ during the FSW process. The optimized welding parameters for obtaining defect-free 316L-RAFM dissimilar joints by FSW are $400 \mathrm{rpm}$ rotational speed, $100 \mathrm{~mm} / \mathrm{min}$ travel speed, and using the butt joining mode of $316 L(A S)-R A F M(R S)$.

\subsection{Microstructures}

Figure 7 shows the microstructures of the $R A F M(A S)$ $316 L(R S)$ weld. There were seven distinct regions that can be identified by OM observations. As shown in Fig. 7a, the microstructure of the HAZ on the RAFM side (HAZRAFM) consisted of fine-grained ferrite and lath martensite,
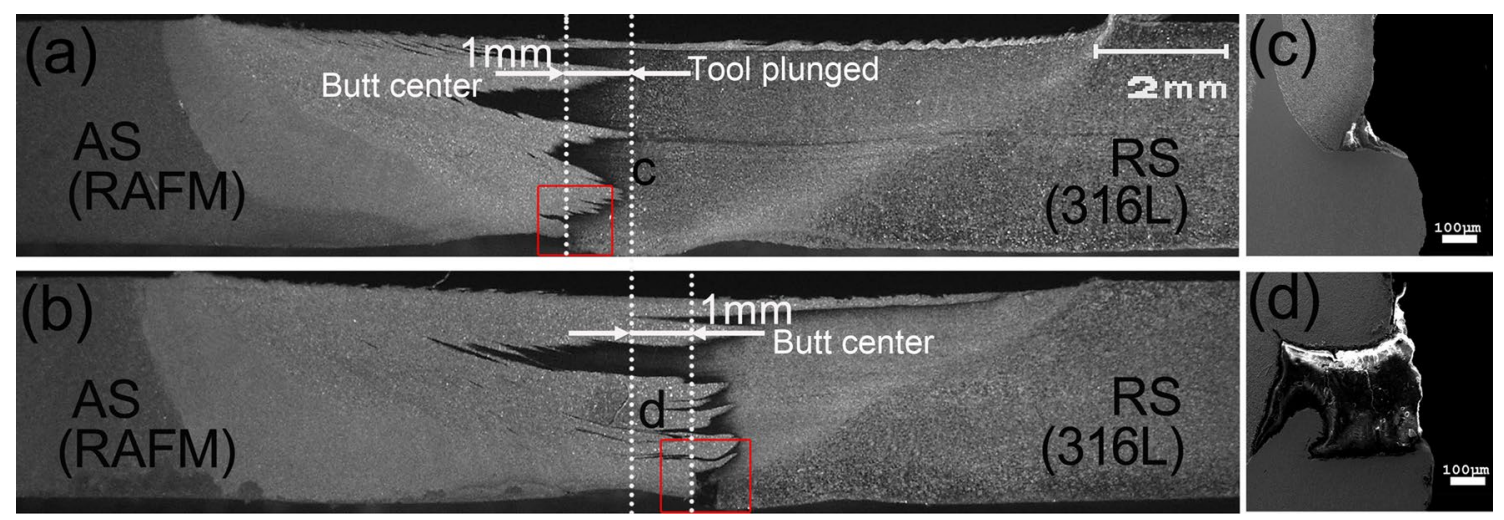

Fig. 6 Cross sections of RAFM-316L dissimilar FSW joint at a rotational speed of $300 \mathrm{rpm}$ and a travel speed of $75 \mathrm{~mm} / \mathrm{min}$ : a $R A F M(A S+1)$ $316 L(R S), \mathbf{b} R A F M(A S)-316 L(R S+1), \mathbf{c}, \mathbf{d}$ SEM images of rectangular regions $\mathbf{c}$ and $\mathbf{d}$ in $\mathbf{a}$ and $\mathbf{b}$, respectively 

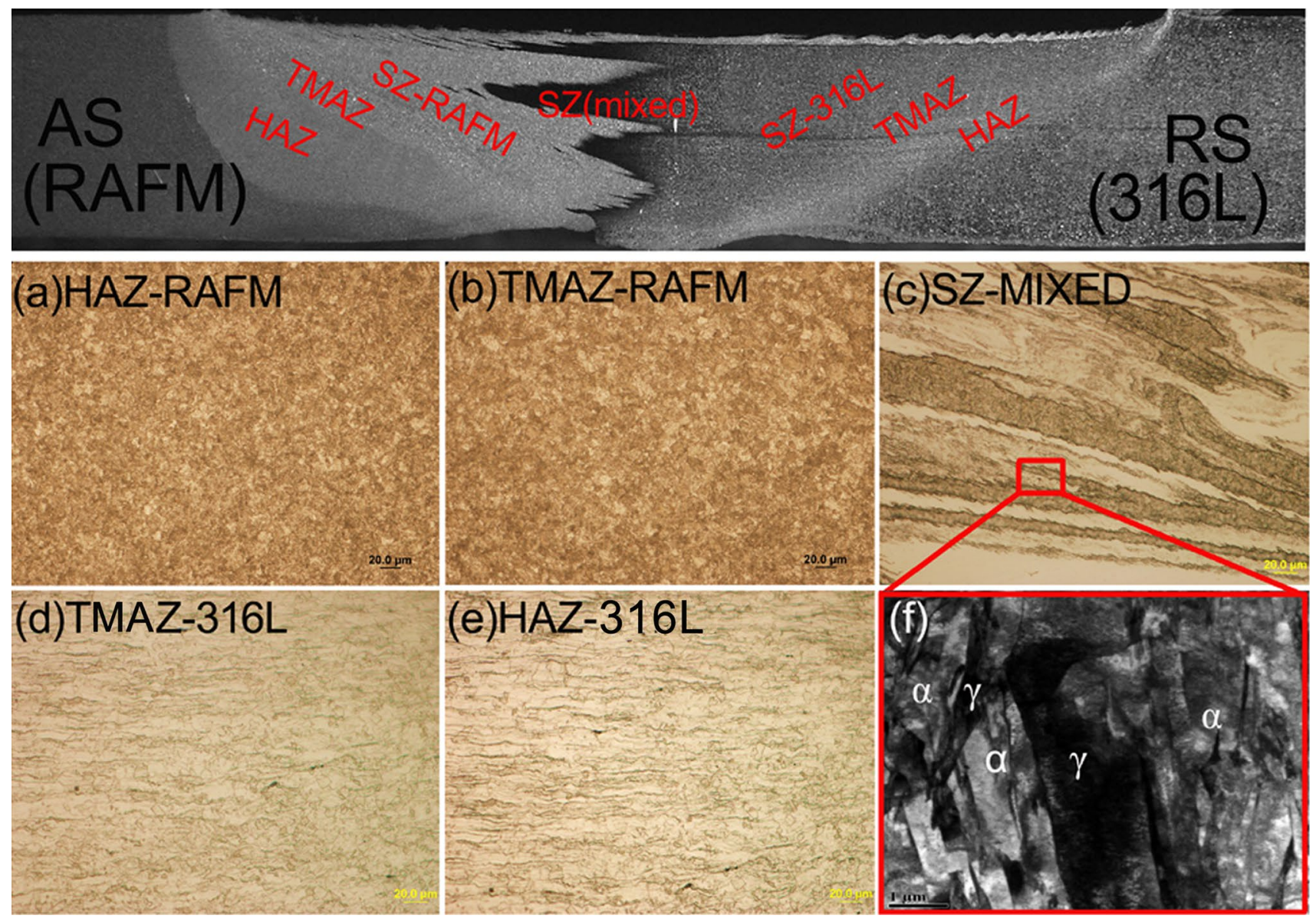

Fig. 7 Microstructures in $R A F M(A S)-316 L(R S)$ weld: a HAZ-RAFM, b TMAZ-RAFM, c SZ-RAFM, d TMAZ-316L, e HAZ-316L. f TEM image of the mixed structure observed in $\mathbf{c}$

indicating that partial recrystallization occurred in this region because the welding peak temperature was approximately $A_{\mathrm{C} 1}$ of the RAFM steel during the FSW process [2]. The microstructural evolution involved a part of the tempered martensite that was present in the BM transforming to austenite during the welding heating cycle and then transforming to lath martensite during the rapid cooling process. In the TMAZ of the RAFM side (TMAZ-RAFM), as shown in Fig. 7b, the microstructure was characterized by a large volume of lath martensite. Because the TMAZRAFM underwent higher welding peak temperatures and lower cooling rates than the HAZ-RAFM, the grains were somewhat larger than those in the HAZ-RAFM [2].

The microstructure of the $\mathrm{SZ}$ adjoining the bonding interface and consisting of a mixture of RAFM steel and $316 \mathrm{~L}$ stainless steel is shown in Fig. 7c. The corresponding TEM image of the same region is shown in Fig. 7f. The grain structure of this region was characterized by a mixture of lath martensite and equiaxed austenite, which transformed from the RAFM steel and 316L stainless steel, respectively, during the FSW process. Most areas in the SZ comprised of a mechanical mixture of RAFM steel and 316L stainless steel. However, in parts of the mixed region, a dualphase structure consisting of austenite and ferrite can also be observed under TEM. This indicated that diffusion of $\mathrm{Cr}$ and $\mathrm{Ni}$, which played a key role in the formation of ferrite and austenite, was achieved from the 316L matrix to the RAFM matrix during the FSW process. Details of the alloy element distribution across the bonding interface will be discussed in the following sections.

Figure 7d, e shows the microstructures of the TMAZ and HAZ on the $316 \mathrm{~L}$ stainless steel side of the joint, which are marked for TMAZ-316L and HAZ-316L, respectively. The banded structures in the TMAZ-316L and HAZ-316L that were present in the BM-316L steel and parallel to the rolling direction (see Fig. 1) became indistinguishable after FSW. Moreover, in the HAZ-316L and TMAZ-316L, some of the fine austenite grains can be observed between the relatively large austenite grains (Fig. 7d, e). This indicated that partial recrystallization of austenite also occurred in the TMAZ316L and HAZ-316L during the FSW process. However, the grain coarsening was not obvious. 
Figure 8 shows the microstructures of the $\mathrm{SZ}$ in the upper part, middle part, and bottom part of the RAFM(AS)$316 L(R S)$ joint. The results show that the microstructure of the SZ-RAFM mainly consisted of lath martensite and ferrite, and in the SZ-316L, it was entirely austenite. As shown in Fig. 8a-c, in the SZ-RAFM, from the top to the bottom of the joint, the grain size first increased and then decreased. The largest grain size in the SZ-RAFM was achieved in the middle part of the joint because the cooling rate in this area may be lower than that in the top and bottom parts of the joint. As shown in Fig. 8d-f, from the top part to the bottom part of the SZ-316L, the austenite grain size decreased.

Table 3 summarizes the average grain size of the SZ$316 \mathrm{~L}$ in the joints welded with different joining modes and welding parameters. The average grain size of the SZ$316 \mathrm{~L}$ in the joints welded with the $316 L(A S)-R A F M(R S)$ mode $(6.1-6.3 \mu \mathrm{m})$ was generally smaller than that with the $R A F M(A S)-316 L(R S)$ mode $(7.5-8.4 \mu \mathrm{m})$. The different extents of the grain refinement with different welding parameters were closely related to the recrystallization process and grain growth, which was governed by the plastic flow and temperature history during the FSW process. As proposed by Miles et al. [18], the average size of the recrystallized grains in the SZ of an austenitic stainless steel FSW joint was mainly governed by the strain rate and temperature. Within a certain temperature range, an increase in the strain rate might lead to a significant decrease in the grain size. Moreover, if the temperature and strain rate decreased simultaneously, the grain size might also decrease obviously.

\subsection{Bonding of the Interface}

Figure 9a, c shows SEM images of typical microstructures of mixed 316L stainless steel and RAFM steel. The alloying element distribution across the mixed area obtained by EDS line scanning is shown in Fig. 9b, d. In the region that
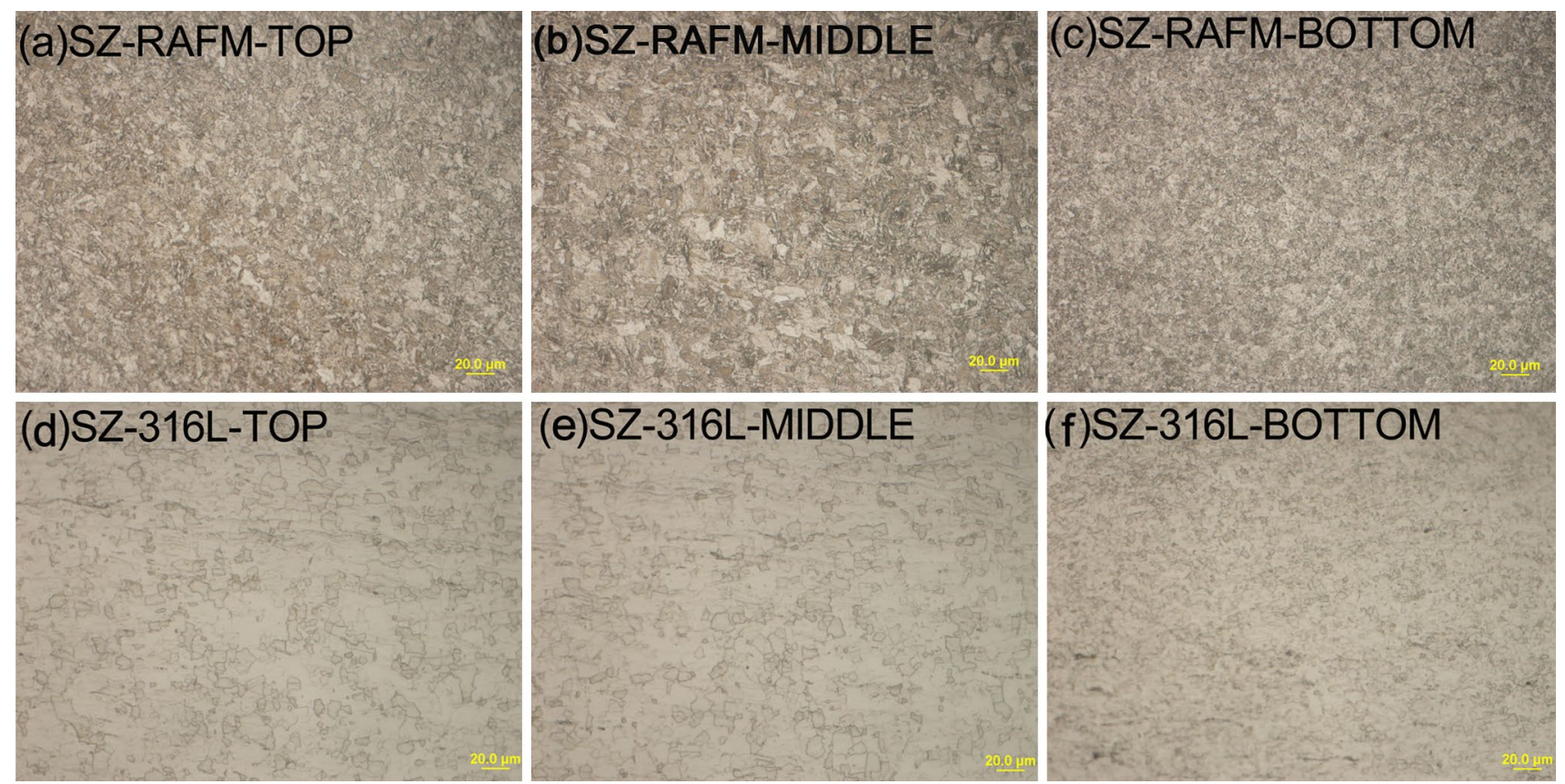

Fig. 8 Microstructures in SZ at the top, middle, and bottom of $R A F M(A S)-316 L(R S)$ weld: a SZ-RAFM-TOP, b SZ-RAFM-MIDDLE, c SZRAFM-BOTTOM, d SZ-316L-TOP, e SZ-316L-MIDDLE, f SZ-316L-BOTTOM

Table 3 Average grain size of austenite in SZ-316L

\begin{tabular}{llcl}
\hline Butt joining types in FSW & $\begin{array}{l}\text { Rotational speed } \\
(\mathrm{rpm})\end{array}$ & $\begin{array}{l}\text { Travel speed }(\mathrm{mm} / \\
\mathrm{min})\end{array}$ & $\begin{array}{l}\text { Average austenite grain } \\
\text { size in SZ-316L }(\mu \mathrm{m})\end{array}$ \\
\hline$R A F M(A S)-316 L(R S)$ & 300 & 75 & $8.1 \pm 0.56$ \\
$316 L(A S)-R A F M(R S)$ & 300 & 75 & $6.3 \pm 0.53$ \\
$R A F M(A S+1)-316 L(R S)$ & 300 & 75 & $7.8 \pm 0.69$ \\
$R A F M(A S)-316 L(R S+1)$ & 300 & 75 & $8.4 \pm 0.81$ \\
$R A F M(A S)-316 L(R S)$ & 400 & 100 & $7.5 \pm 0.20$ \\
$316 L(A S)-R A F M(R S)$ & 400 & 100 & $6.1 \pm 0.67$ \\
\hline
\end{tabular}



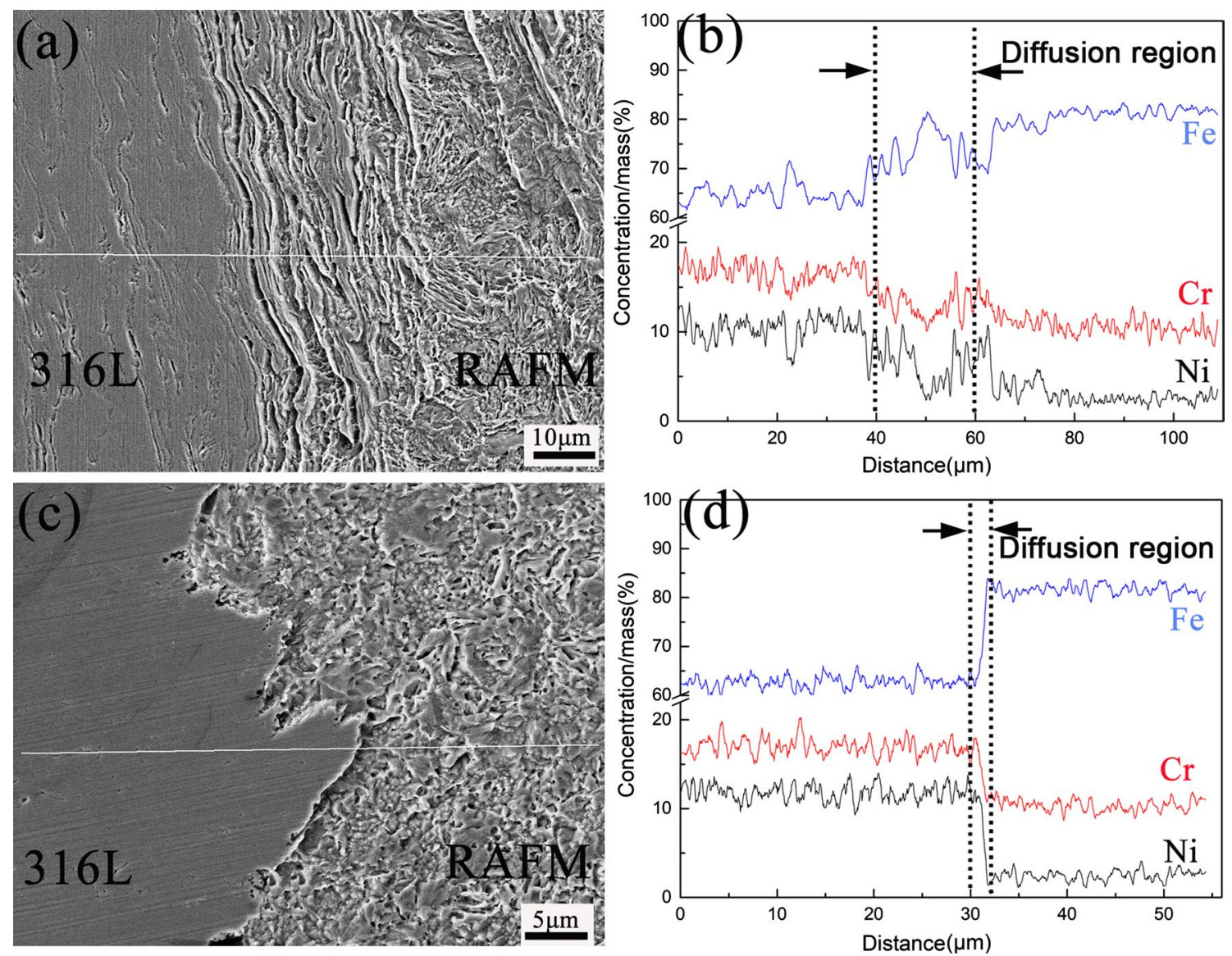

Fig. 9 a SEM image of the interface in the middle of SZ, b EDS results of the interface in the middle of SZ, $\mathbf{c}$ SEM image, $\mathbf{d}$ EDS results for the interface near the bottom of SZ

was highly mixed with the two materials (Fig. 9a, b), the curves of $\mathrm{Cr}$ and $\mathrm{Ni}$ content exhibit dramatic fluctuations, indicating that most of the $\mathrm{Cr}$ and $\mathrm{Ni}$ were still dissolved within the matrix of the $316 \mathrm{~L}$ stainless steel. However, when approaching the austenite and martensite interface, the change in the $\mathrm{Cr}$ and $\mathrm{Ni}$ content became continuous within a range of $\sim 10 \mu \mathrm{m}$, and the concentrations of $\mathrm{Cr}$ and $\mathrm{Ni}$ within the martensite blocks were higher than those in the BM-RAFM. This indicates that in addition to the mechanical mixture of the two materials, diffusion of $\mathrm{Cr}$ and Ni from 316L stainless steel to RAFM steel occurred during the FSW process.

The bonding interface close to the weld bottom of the 316L-RAFM dissimilar joint was also examined by SEM and EDS, as shown in Fig. 9c, d. The EDS line scanning results indicate that $\mathrm{Cr}$ and $\mathrm{Ni}$ may diffuse from the $316 \mathrm{~L}$ stainless steel side to the RAFM steel side. However, the diffusion distance across the bottom interface $(\sim 2.5 \mu \mathrm{m})$ was shorter than that in the middle region, as observed in Fig. 9a, b. This illustrates that although metallurgical bonding of 316L stainless steel and RAFM steel was achieved at the bottom of the weld, the extent of alloying element diffusion was limited owing to the decreased temperature and increased cooling rate in this area during the FSW process.

To explore the formation of the dual-phase structure consisting of ferrite/martensite and austenite, as shown in Fig. 7f, more details regarding the diffusion of $\mathrm{Cr}$ and $\mathrm{Ni}$ near the bonding interface were examined by EDS. It can be observed in Fig. 10 that, in the selected area on the RAFM steel side, which was $\sim 15 \mu \mathrm{m}$ far from the bonding interface, the $\mathrm{Ni}$ content increased to $0.35 \%$ in weight. Moreover, the $\mathrm{Ni}$ content of the selected area on the 316L stainless steel side decreased to $3.22 \%$ in weight, which was obviously lower than that of the BM-316L ( 12\% in weight). The above results showed that a fair amount of $\mathrm{Ni}$ in BM-316L diffused into the matrix of the RAFM steel.

One key aspect to be noted here is that $\mathrm{Ni}$ is the most important alloying element to form and stabilize austenite in steels. On the edge of $316 \mathrm{~L}$ stainless steel side close to the bonding interface, the absence of Ni reduced the stability of austenite, and the final $\mathrm{Cr}$ and $\mathrm{Ni}$ contents $(\mathrm{Cr} 11.88 \%$, $\mathrm{Ni} 3.22 \%$ in weight) provided a favorable composition for the martensitic transformation during the cooling process after FSW [19]. Furthermore, because the Ni content in the 

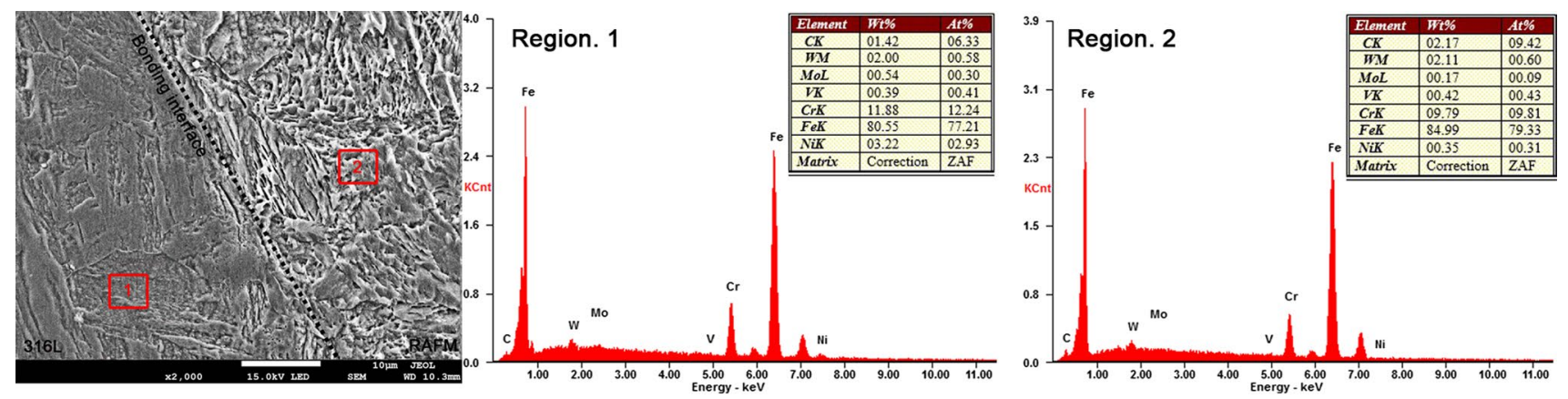

Fig. 10 SEM image and EDS results of the region near the bonding interface

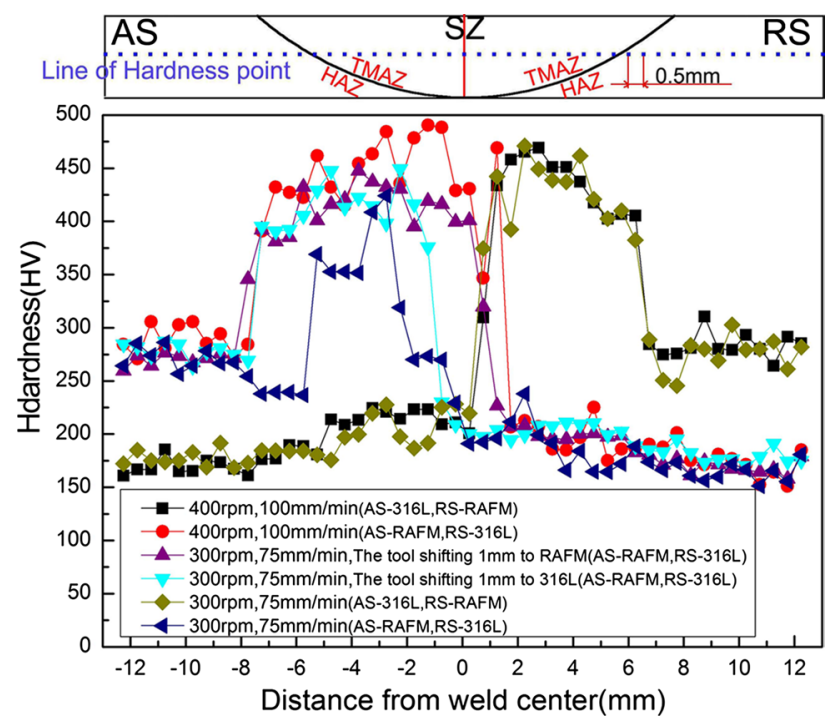

Fig. 11 Hardness distribution of RAFM-316L dissimilar FSW joints

RAFM steel side increased by diffusion during FSW, the amount of retained austenite in the SZ-RAFM near the bonding interface increased. These are considered as evidence of metallurgical bonding of 316L stainless steel and RAFM steel during FSW and one reason for the formation of the dual-phase structure that was found on each side of the FSW joint.

\subsection{Mechanical Properties}

\subsubsection{Hardness}

Figure 11 shows the hardness distribution of the FSW joints. The hardness values of the SZ-RAFM were significantly higher than those of the BM-RAFM, but the increase in the hardness of the SZ-316L was relatively slight. The hardness value of the SZ-316L was in the range of 200-225 HV, nearly $25-50 \mathrm{HV}$ higher than that of the BM-316L. The random fluctuation in the hardness value in the $\mathrm{SZ}$ was caused by the mixture of $316 \mathrm{~L}$ stainless steel and RAFM steel. In some areas of the SZ that were highly mixed, if the hardness testing point was placed on the RAFM steel, a very high hardness value of $\sim 400 \mathrm{HV}$ was obtained owing to the strengthening effect of the martensitic transformation. In addition, in the HAZ-RAFM, an obvious reduction in the hardness value was observed at the edge of the TMAZRAFM, indicating that softening occurred in the HAZ on the RAFM steel side. However, softening could not be observed in the HAZ on the $316 \mathrm{~L}$ stainless steel side.

\subsubsection{Tensile Properties}

The room temperature tensile results of the FSW joints are shown in Fig. 12. The RAFM-316L dissimilar joints had excellent tensile properties, and all the specimens were fractured at the BM of $316 \mathrm{~L}$ stainless steel side. This indicates that high-quality metallurgical bonding between the $316 \mathrm{~L}$ stainless steel and RAFM steel was achieved with the joining modes and welding parameters in this study. The yield strength (YS) of the joints ranged from 425 to $500 \mathrm{MPa}$, and the ultimate tensile strength (UTS) of the joints exceeded $650 \mathrm{MPa}$, which is nearly equal to that of the $316 \mathrm{~L} \mathrm{BM}$. The elongation of the $316 \mathrm{~L}-\mathrm{RAFM}$ dissimilar joints exceeded $40 \%$, because most of the plastic deformation occurred on the $316 \mathrm{~L}-\mathrm{BM}$ during the tensile tests. Moreover, a change in the butt joining mode and welding parameters showed no obvious effects on the tensile properties of the dissimilar joints.

Figure 13 shows the tensile properties at $550{ }^{\circ} \mathrm{C}$ for all the joints. The YS, UTS, and elongation of the joints ranged from $250-300 \mathrm{MPa}, 450-560 \mathrm{MPa}$, and $14.7-17 \%$, respectively. Most of the tensile samples were fractured at the BM-316L and SZ-316L, and the strength of the joints was equal to that of the BM-316L. As shown in Fig. 13a, all the stress-strain curves had the characteristics of serrated plastic flow, which began at a stress slightly higher than the YS point of joint. A widely accepted mechanism of serrated yielding was dynamic strain aging due to the 

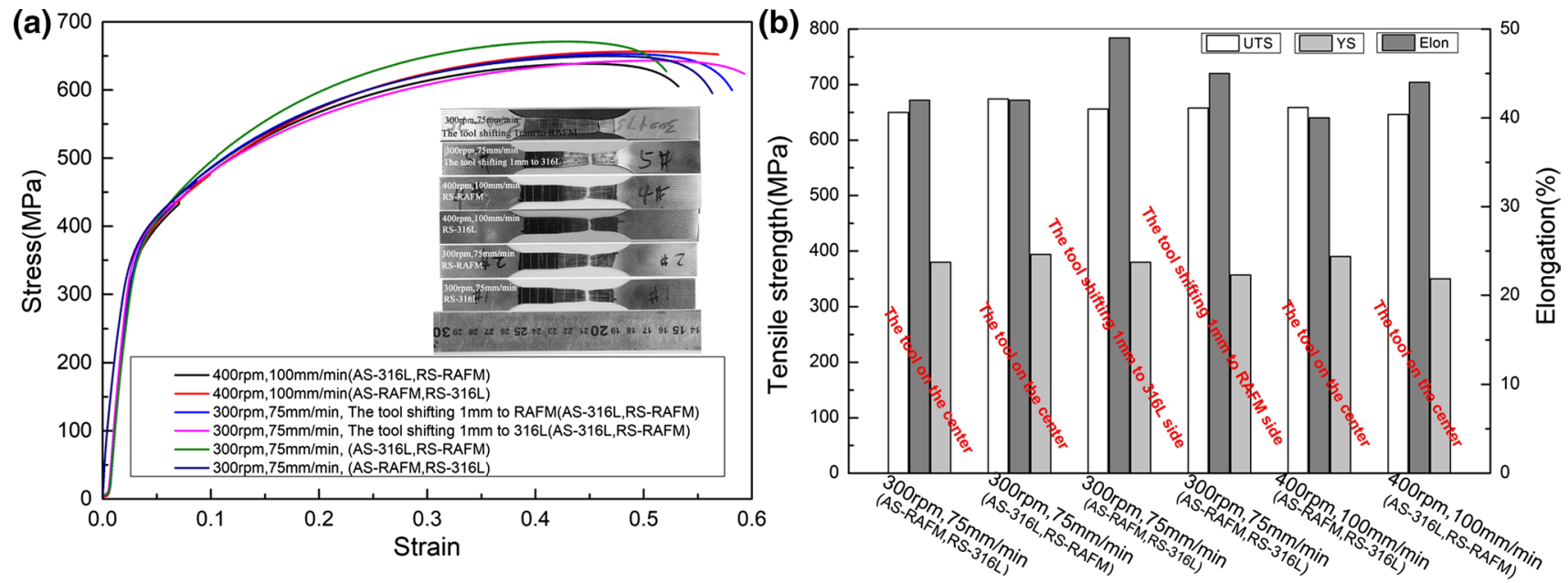

Fig. 12 a Room temperature engineering stress-strain curves, b tensile properties of RAFM-316L dissimilar FSW joints
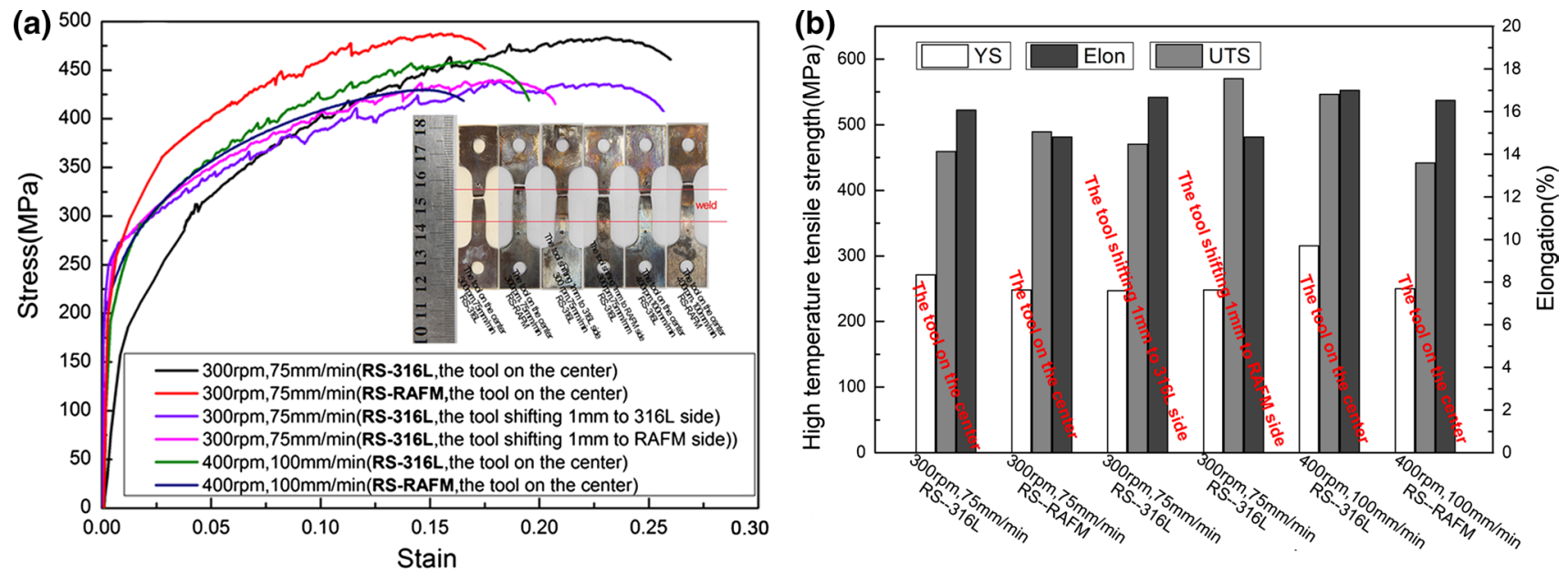

Fig. 13 a Engineering stress-strain curves, b tensile properties of RAFM-316L dissimilar FSW joints at $550{ }^{\circ} \mathrm{C}$

interaction between solute atoms and mobile dislocations during high-temperature plastic deformation process [20]. For $9 \mathrm{Cr}-1$ Mo ferritic steel, as proposed by Choudhary et al. [21], the serrated flow might occur in the tempered temperature range from 300 to $873 \mathrm{~K}$. Moreover, similar behaviors could also be found in austenitic and ferritic heat-resistant steels when they were deformed plastically at elevated temperatures $[22,23]$.

\subsubsection{Impact Toughness}

Figure 14 shows the impact toughness for different regions of the weld tested with 2.5-mm-thick V-notched specimens at a temperature of $-40{ }^{\circ} \mathrm{C}$. The HAZ-RAFM had the lowest impact absorbed energy of $13.2 \mathrm{~J}$. The brittleness of the HAZ-RAFM was mainly caused by the formation of lath martensite structures and the coarsening of $M_{23} \mathrm{C}_{6}$ carbides.
The impact toughness of the SZ-RAFM and TMAZ-RAFM was somewhat higher than that of the BM-RAFM. The main reason for the increase in the impact toughness of the SZRAFM was the increase in the Ni content and grain refinement. For the TMAZ-RAFM, one reason for the increase in the impact toughness that should not be ignored here is that the V-notched position of the impact specimen may have involved a part of the SZ and BM. In the HAZ-316L and TMAZ-316L, the impact toughness was nearly equal to that of the SZ but obviously lower than that of the 316L BM.

Typical SEM fractographs in different regions of the impact samples are shown in Fig. 15. Figure 15a-d shows that the fracture morphology of the joint exhibited the characteristics of ductile fracture, namely dimples, microvoids, and tearing ridges. The results revealed that the SZMIXED, SZ-316L, SZ-RAFM, TMAZ-316L, HAZ-316L, and TMAZ-RAFM of the dissimilar joints exhibited good 


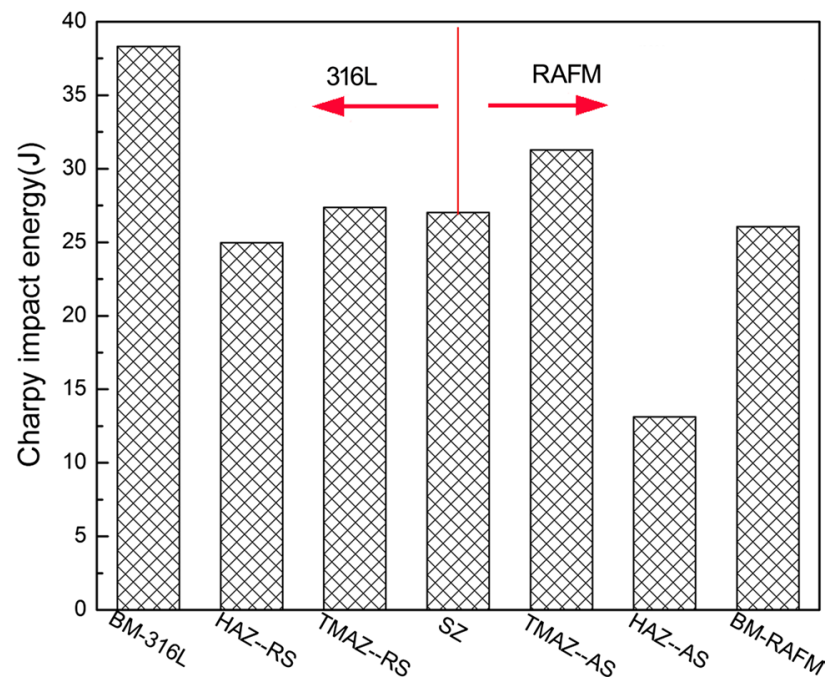

Fig. 14 Impact absorbed energies of the $R A F M(A S)-316 L(R S)$ joint tested at $-40{ }^{\circ} \mathrm{C}$

toughness. However, some cleavage steps are observed in Fig. 15e, which was an indication of the brittleness of the HAZ-RAFM of the dissimilar FSW joint.

\section{Conclusions}

1. The butt joining mode of RAFM steel and $316 \mathrm{~L}$ stainless steel had an obvious influence on the material flow and weld formation for RAFM-316L dissimilar FSW joints. The optimized butt joining mode obtained in this study was placing $316 \mathrm{~L}$ steel on the AS and RAFM steel on the RS of the joint. The recommended welding parameters for improving the material flow and weld formation were $400 \mathrm{rpm}$ rotational speed and $100 \mathrm{~mm} / \mathrm{min}$ travel speed.

2. The microstructure of SZ-316L was entirely austenite. The microstructure of the SZ-RAFM consisted of lath martensite and ferrite. Near the bonding interface, diffusion of the Ni from the $316 \mathrm{~L}$ side to the RAFM side was observed. The absence of $\mathrm{Ni}$ in the SZ-316L and the excess of $\mathrm{Ni}$ in the SZ-RAFM resulted in the formation of a dual-phase structure consisting of martensite/ferrite and austenite adjoining the bonding interface.

3. The RAFM-316L dissimilar FSW joint exhibited good tensile properties at room temperature and $550{ }^{\circ} \mathrm{C}$. The strength and ductility of the joint was equal to those of 316L BM. The HAZ-RAFM had the lowest impact toughness throughout the weld, which was $13.2 \mathrm{~J}$ when tested with a 2.5 -mm-thick V-notched specimen at $-40{ }^{\circ} \mathrm{C}$.
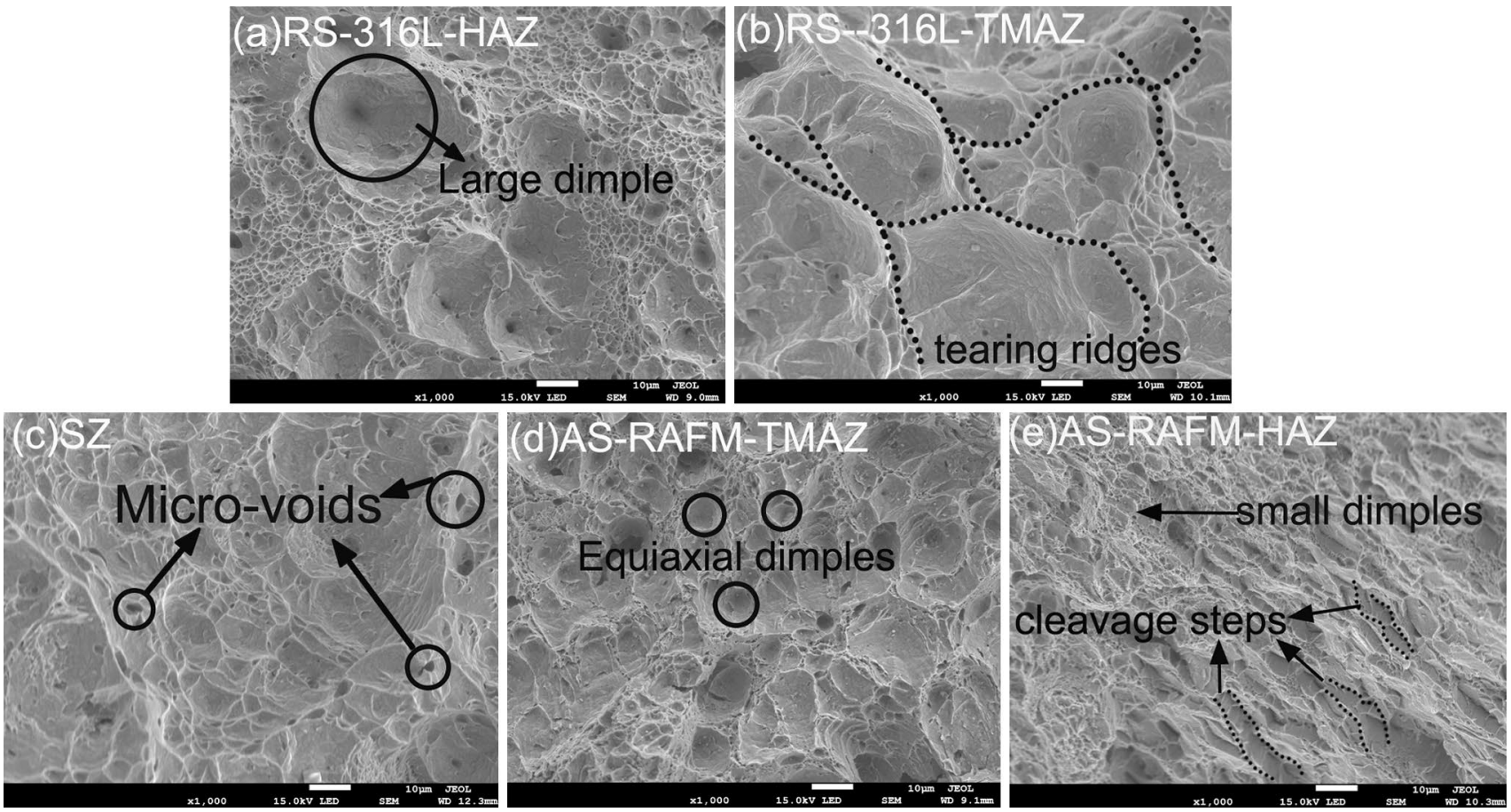

Fig. 15 SEM observations of impact fractography in different regions 
Acknowledgements This work was financially supported by the National Natural Science Foundation of China (Nos. 517011741, U1660201) and the National Magnetic Confinement Fusion Energy Research Project (No. 2015GB119001).

\section{References}

[1] H. Fu, T. Nagasaka, M. Yamazaki, Fusion Eng. Des. 124, 1063 (2017)

[2] C. Zhang, L. Cui, D. Wang, Scr. Mater. 158, 6 (2019)

[3] C.L. Chen, A. Richter, R. Kögler, J. Alloys Compd. 615, S448 (2014)

[4] G.L. Liu, S.W. Yang, W.T. Han, Mater. Sci. Eng. A 722, 182 (2018)

[5] Y. Kumar, S. Venugopal, G. Sasikala, Mater. Sci. Eng. A 731, 551 (2018)

[6] S.K. Albert, C.R. Das, S. Sam, Fusion Eng. Des. 89, 1605 (2014)

[7] Y. Mei, Y. Liu, C. Liu, Mater. Des. 89, 964 (2016)

[8] S.S. Kumar, N. Murugan, K.K. Ramachandran, J. Mater. Process. Technol. 254, 79 (2018)

[9] C. Zhang, L. Cui, Y. Liu, J. Mater. Sci. Technol. 34, 756 (2018)
[10] Y.D. Chung, H. Fujii, Y. Sun, H. Tanigawa, Mater. Sci. Eng. A 528, 5812 (2011)

[11] M. Jafarzadegan, A. Abdollah-zadeh, A.H. Feng, J. Mater. Sci. Technol. 29, 367 (2013)

[12] W. Tang, X. Yang, S. Li, J. Mater. Process. Technol. 271, 189 (2019)

[13] E.Z. Gao, X.X. Zhang, C.Z. Liu, Z.Y. Ma, Trans. Nonferr. Metal. Soc. 28, 2324 (2018)

[14] J.H. Cho, D.E. Boyce, P.R. Dawson, Mater. Sci. Eng. A 398, 146 (2005)

[15] F.C. Liu, T.W. Nelson, Mater. Des. 110, 354 (2016)

[16] L. Cui, C. Zhang, Y.C. Liu, J. Iron. Steel Res. Int. 25, 477 (2018)

[17] Y. Huang, Y. Xie, X. Meng, J. Mater. Sci. Technol. 35, 1261 (2019)

[18] M.P. Miles, T.W. Nelson, C. Gunter, J. Mater. Sci. Technol. 35, 491 (2019)

[19] H. Zhang, C.H. Zhang, Q. Wang, Opt. Laser Technol. 101, 363 (2018)

[20] C. Mao, C. Liu, LYu. Mater, Sci. Eng. A 739, 90 (2019)

[21] B.K. Choudhary, Mater. Sci. Eng. A 564, 303 (2013)

[22] T. Sakai, A. Belyakov, R. Kaibyshev, Prog. Mater Sci. 60, 130 (2014)

[23] Z.Q. Xu, Y.Z. Shen, Metals 8, 13 (2018) 